\title{
From Fields to Farms: Informing the Trade-Offs Across the Multiple Functions of Agriculture ${ }^{+}$
}

\author{
Daniel Rodriguez \\ Queensland Alliance for Agriculture and Food Innovation (QAAFI), The University of Queensland Gatton, \\ Gatton, QLD 4343, Australia; d.rodriguez@uq.edu.au; Tel.: +61-434075094 \\ + Presented at the third International Tropical Agriculture Conference (TROPAG 2019), Brisbane, Australia, \\ 11-13 November 2019.
}

Published: 19 January 2020

Keywords: APSFarm; APSIM; whole farm modelling; farmers; decision making; profits; risks

Adapting the nature and extent of agriculture to fit expected increases in food and energy demand, amid changes in climate and the environment, clearly requires the development and application of new scientific approaches and innovative solutions. High productivity is the result of the best combination of management variables that influence crop production in a given field, and the way limited resources e.g. labour, land, finances, are allocated across enterprises and fields at the whole-farm level. Focusing on the yield of individual crops is necessary but insufficient for several reasons. First, larger improvements in productivity are likely from interventions at scales beyond the crop or the field, i.e. the farming system, the farm, and their operating environment. Second, changes in the yield of individual crops might not reflect the fact that farmers manage the farm and resources to satisfy a number of usually competing objectives: livelihoods, returns, lifestyle, environmental outputs, rather than just increasing crop yields. This is important as changes in one enterprise at any point in time will limit options spatially across the farm e.g. due to land, labour or machinery constraints; and temporally across seasons e.g. due to follow-on implications on soil water and nutrients availability, or the need for breaks for pests or diseases between successive crops. Thus, when the analysis is removed from the farm business context, the disconnect between the more technical issues, e.g. choosing a cultivar or a particular rate of fertilisation, and the final decision made on the farm, can conspire against understanding why an individual piece of technology is not adopted, or why apparently a "sub-optimal" decision is finally made. Recognising that farmers grow crops in cropping systems, that they usually manage limited resources and that those resources need to be allocated to satisfy their multiple objectives across a number of alternative enterprises is the first step in understanding where the opportunities for improvement may lie. Farms are complex systems (Figure 1), that is why the analysis requires involving all actors in participatory research approaches working with farmers at the level that they think and make decisions i.e. the farm business. 


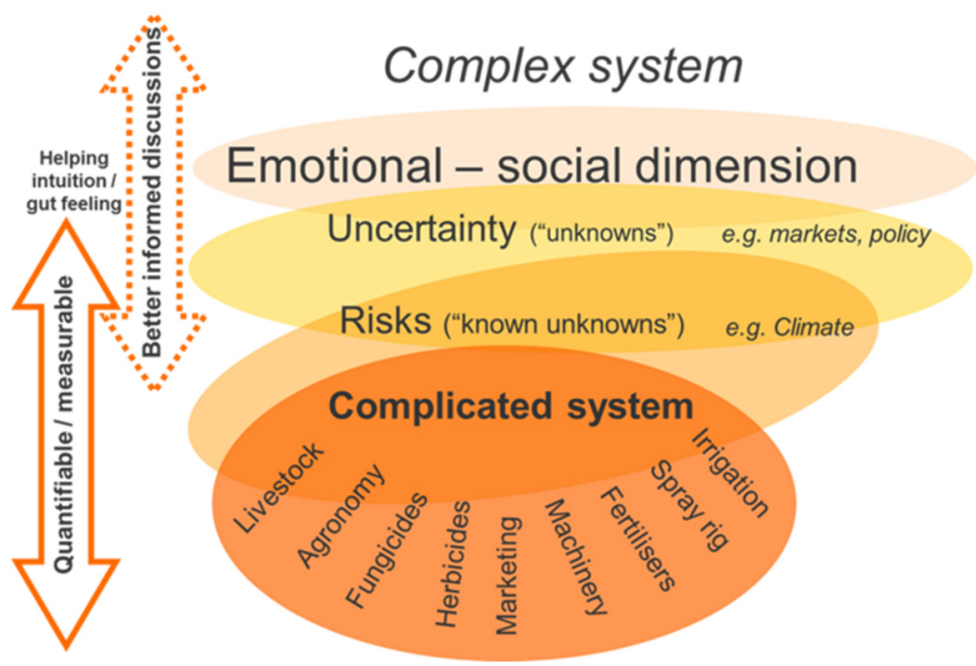

Figure 1. Conceptualization of the complexities in the management of a farm business and its disaggregation into quantifiable or measurable components, and the social-human dimension accessible via discussion, reflexion, and learning.

(C) 2020 by the authors. Licensee MDPI, Basel, Switzerland. This article is an open access article distributed under the terms and conditions of the Creative Commons Attribution (CC BY) license (http://creativecommons.org/licenses/by/4.0/). 